\title{
Synthesis of cellulose from office waste paper and the effect on mechanical properties of cellulose/kenaf/epoxy composite
}

\author{
Vicki.W.V., Taness Santhana Rajah, and Selvakumar. S. \\ Centre for Advance Material (CAM), College of Engineering, Universiti Tenaga Nasional, Malaysia
}

\begin{abstract}
Environmental and open public health aspects have an important and increasing role, especially in the exploration of natural fibers from recycle materials. The aim of this study is to synthesis cellulose from office waste paper and use it as a reinforcement filler to develop biocomposites. Epoxy reinforced kenaf fiber and cellulose composite were prepared in this study using polymer casting technique consisting of grinded kenaf fibre (natural fibre) $5 \%$ and epoxy $95 \%$ as reinforcement element. Cellulose was synthesized from recycled office papers and used as a filler to prepare cellulose/kenaf reinforced epoxy composite. Effect of cellulose to the mechanical properties of the composite were investigated. Samples were fabricated by weight percentage of $0 \%, 0.5 \%, 1.0 \%, 1.5 \%$ and $2.0 \%$ of cellulose content. For mechanical properties impact test, Rockwell harness and tensile testings were conducted.
\end{abstract}

\section{Introduction}

In the modern era, environmental issues have become imperative in each innovative part, especially in advanced materials. Waste paper recycling has a positive impact on environmental and economical benefits as recycling of one ton of waste paper saves almost 17 trees and 7000 gallons of water [1]. Recently, natural fibre reinforced polymer composites have been extended to advanced applications, such as in automotive, aircraft, medical and food industries, and also to reinforce polymer [2]. The expansion in ecological awareness and community interest, new environmental regulations and unsustainable consumption of petroleum, led to the thinking of the use of environmentally friendly materials. Normal fibre is seen as one of the naturally inventing materials, which have great properties contrasted with manufactured fibre to synthetic fibre. Fibre sort is usually categorized in view of its source plant, animal or mineral. All plant fibres contain cellulose as their major basic structural component, whereas animal fibres mainly consist of protein. Although mineral-based natural fibres characteristic strands exist inside the asbestos group of minerals and were once utilized broadly in composites, these are currently avoided because of related medical problems associated with health issues due to its carcinogenic effects through inhalation/ingestion and are banned in many countries [3]. Generally, significantly higher qualities and stiffness are reachable with the higher execution plant

*Corresponding author: Vignesh@uniten.edu.my 
filaments with the higher performance plant fibres than the available animal fibres. An exception to this is silk, which can have very good mechanical strength, but is very expensive. Moreover, it has lower stiffness and is rare to find. This makes plant-based fibre a good material for use in structural composites. Furthermore, plant fibre can be suitably grown in many countries and can be harvested after short periods. Natural fibres have been used as reinforcing materials for over 3000 years, in combination with polymeric materials. In the course of nature, composite materials were subjected to both mechanical loadings and exposed to severe environmental conditions. The natural fibre reinforced composite is lightweight and free from health hazard, reasonably strong, therefore has the potential to be used as a material for strong components such as building materials, shipping, and automotive [4]. Despite the advantages, they suffer from some limitations such as poor moisture resistance especially absorption and low strength compared to synthetic fibre such as glass. Kenaf fibres are acquired from the Hibiscus cannabinus, a quick growing plant ready to achieve $3.5 \mathrm{~m}$ of height in 2 years [5]. Kenaf composites have demonstrated superior flexural properties compared to other natural fibre composites and reinforced fibres. Besides, the fibres high cellulose content and good orientation of microfibrils in kenaf are the main reasons kenaf composites demonstrate high flexural modulus [6]. Furthermore, the higher concentration of crystallization temperature is observed in kenaf fibres composites. This is related to the high crystalline content of kenaf Fibres. Both composites also showed higher storage modulus, (E') as a function of temperature due to the high energy absorption ability of kenaf fibre [7].

\section{Materials}

Epoxy is a combination of both the resin (Bisphenol A-epichlorhydrine) and hardener (triethylenetetramine). Bondite 8950-1 A (resin) and Bondite 8950-1 B (hardener) are supplied by Miracon (M) Sdn Bhd. The mixing ratio of both this resin and hardener is 100:50. The resin is in light purple color and the hardener is clear. The pot life of epoxy is $80-100$ minutes. The kenaf short fibre $(3-5 \mathrm{~mm})$ was purchased from Innovative Pultrusion Sdn Bhd. Office waste paper used in the cellulose extraction was obtained from Universiti Tenaga Nasional.

\section{Cellulose extraction}

Office waste paper was used as the raw material for extraction of cellulose by a simple and economical method. The paper $(10.0 \mathrm{~g})$ was cut into small pieces and mixed with sodium hydroxide solution $(7.5 \%)$ in a plastic container equipped with stirrer. The mixture was stirred for $6 \mathrm{~h}$ then filtered. The filtrate was titrated with sulphuric acid $(5.0 \mathrm{M})$ solution until the $\mathrm{pH}$ reached 5.0. After separating the mixture, the solid was washed with distilled water and dried at room temperature. This method gave about $2.0 \mathrm{~g}(20.0 \%)$ of cellulose. The cellulose extraction method was based on the technique used by the researchers Hathama Razooki Hasan and Muna Hasoon [8].

\section{Cellulose/kenaf/epoxy composite preparation}

Epoxy polymer matrix was prepared by mixing 100:50 parts by volume of epoxy resin with hardener. Epoxy resin contains one or more epoxide groups that serve as cross-linking points when the resin reacts with the hardener to form long chains, the polymerization. The hardener has an impact on the matrix structure and the crosslinking ratio and by this way the molecular motions. A procedure of two steps was followed. The kenaf fibers were first 
dispersed in the epoxy resin and hardener mixture. Cellulose was then added to the mixture and finally, it was injected into sample moulds after manual homogenization. The samples were left to cure for 24 hours at room temperature. Hardened samples were removed from the mould and proceeded for testing. Table 1 shows the mixing ratio of the matrix and filler.

Table 1. Composition of matrix and filler in weight percentage.

\begin{tabular}{|c|c|c|c|}
\hline Samples & Epoxy $(\mathrm{wt} \%)$ & kenaf fiber $(\mathrm{wt} \%)$ & cellulose $(\mathrm{wt} \%)$ \\
\hline 1 & 95 & 5 & 0 \\
\hline 2 & 95 & 5 & 0.5 \\
\hline 3 & 95 & 5 & 1.0 \\
\hline 4 & 95 & 5 & 1.5 \\
\hline 5 & 95 & 5 & 2.0 \\
\hline
\end{tabular}

\section{Results and discussion}

\subsection{Impact test}

Impact test was conducted by using Zwick Roell HIT50P IZOD impact test machine. The Izod impact test is a vibrant test in which a test V-notched test piece, gripped vertically, is damaged by a single $25 \mathrm{~J}$ blow of a freely swinging pendulum. The specimen impact strength was calculated by dividing the impact energy of the specimen per joule with the cross section area of the specimen. This test is to measure the strength of the specimens mechanical properties which presents the crack area brings to fracture because of the sudden impact. The specimens fracture level was penetrated by the interaction of bonding and impact strength between the bonding of the cellulose and kenaf fibre strength. Figure 1 shows the impact strength of the specimen of $0 \%, 0.5 \% .1 \%, 1.5 \%$ and $2 \%$ weight percentage of cellulose composition. The graphs presented the impact strength of all samples with different percentage of cellulose composition. The impact strength of pure kenaf/epoxy composite without cellulose reinforcement has the highest impact strength of $0.09 \mathrm{~J} / \mathrm{mm} 2$. Meanwhile there is huge drop in the impact strength in the specimen which is $2.0 \%$ weight percentage of cellulose composition. The impact strength tend to be decreasing with the increase in cellulose content in weight percentage. Low interface shear stress presented the effect of cellulose on kenaf fibre and epoxy thus these composites reduces the impact strength and brings out the frailty to the composites. This brings to the lowest impact strength which shown in specimen which contain $2.0 \%$ of cellulose composition $0.03 \mathrm{~J} / \mathrm{mm} 2$. This can be concluded that incorporation of cellulose into kenaf fibre and epoxy causes big devaluation of the molecular mobility with successive change in fracture action of the ductile breakable.

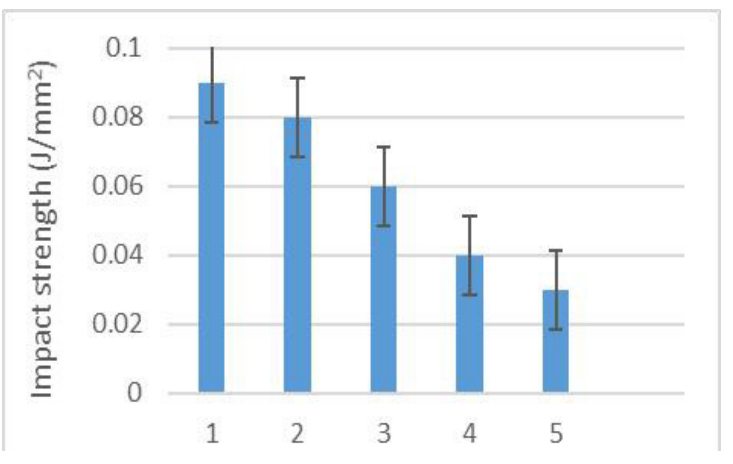

Fig. 1. Impact strength of cellulose/kenaf/epoxy composite. 


\subsection{Rockwell hardness test}

Rockwell hardness testing is due to gauge bulk hardness of the specimen. The test was conducted by using ASTME-18 ZWICK Roell hardness test machine. By loading up the indentation loads, we were able to record the readings of the hardness properties of the sample. Figure 2 shows the hardness values of the samples and the different composition percentage values of samples. The hardness values of the samples is found to be decreasing moderately when the reinforcement of cellulose to the kenaf/epoxy composite are increased. Specimen 5 with $2 \%$ weight percentage of cellulose was having the lowest reading compared to other samples. The graph shows the Specimen 1 with $0 \%$ weight percentage of cellulose is the toughest compared to other samples. This concludes that incorporation of the cellulose increases elasticity of the specimen. The production of the filler into the matrix does not give a great reading and lower interfacial adhesion which makes the hardness value decrease. The $0 \%$ weight percentage cellulose sample average reading is 18.7.4 HRB with highest reading justified to be less tough which was observed for the less impact energy contained for this sample. This showed that the $2.0 \%$ weight percentage of cellulose sample are tougher than $0 \%$ weight percentage of cellulose sample which was the controlled variable in this case.

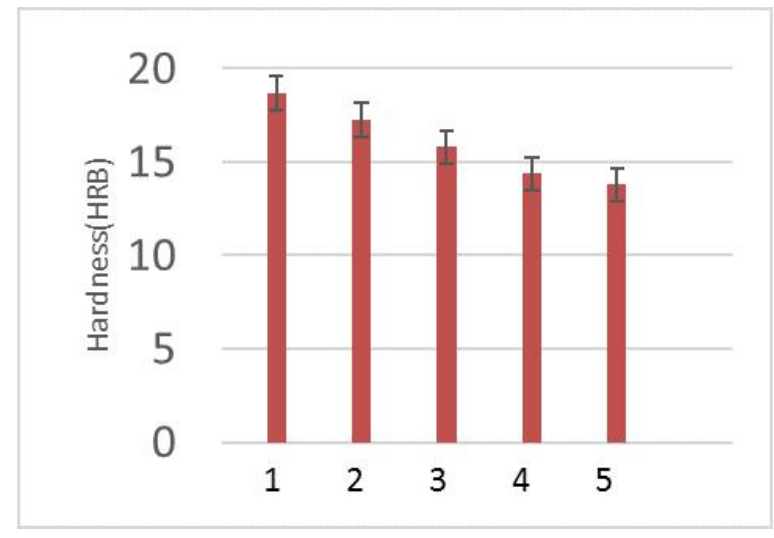

Fig. 2. Hardness of cellulose/kenaf/epoxy composite.

\subsection{Tensile test}

Tensile tests were conducted using the universal testing machine with a crosshead speed of $5 \mathrm{~mm} / \mathrm{min}$. The tensile test samples were cut as per ASTM D638M standard. The tensile test was carried out at room temperature and each test was implemented until tensile specimen fails or breaks. Figure 3 shows the ultimate tensile strength for all the samples with different cellulose loading. Sample 1 and 2 has the highest tensile strength of $21 \mathrm{Mpa}$. The value of tensile strength for sample 2 is almost the same with sample 1 and this indicates that $0.5 \%$ weight loading of cellulose does not have a significant effect to the tensile properties of the composite. However, further increase of the cellulose loading tend to show a slight reduction in the tensile strength of kenaf/epoxy composite. The percentage of elongation of all the samples can be observed in Figure 4. The results show the highest percentage of elongation for sample 1 which is pure kenaf/epoxy composite. The percentage of elongation reduces with the increase in cellulose composition and the highest percentage of elongation was observed in sample 5 . The reduction in the elongation shows that ducitility of the composite is reduced and addition of cellulose makes the composite more brittle. Figure 5 shows that the Young's modulus of elasticity for kenaf/epoxy 
composite without cellulose reinforcement are higher than samples with cellulose due to the fact that lower strain to failure occurred as a result of brittle failure mechanism.

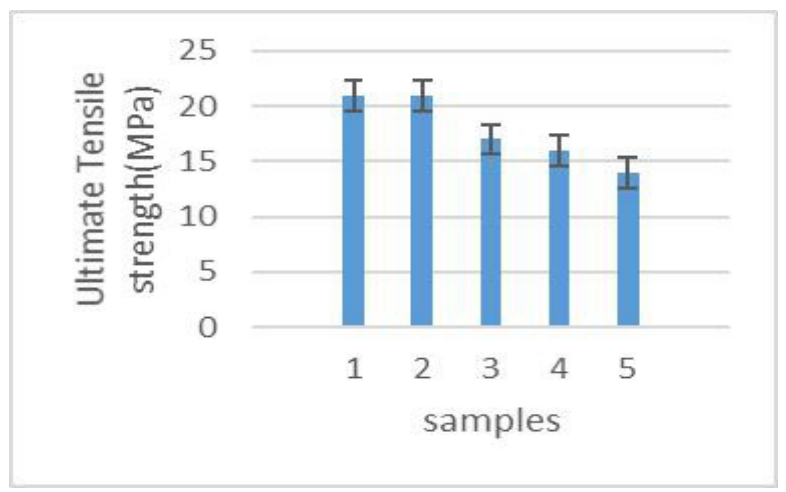

Fig. 3. Ultimate tensile strength.

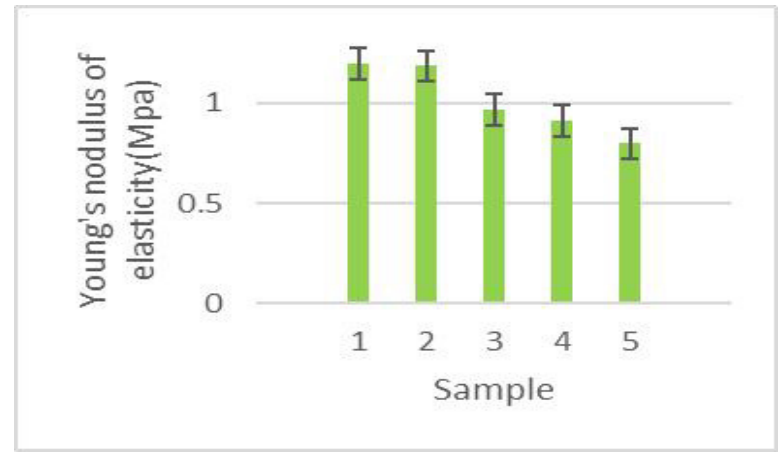

Fig. 4. Young' modulus of elasticity.

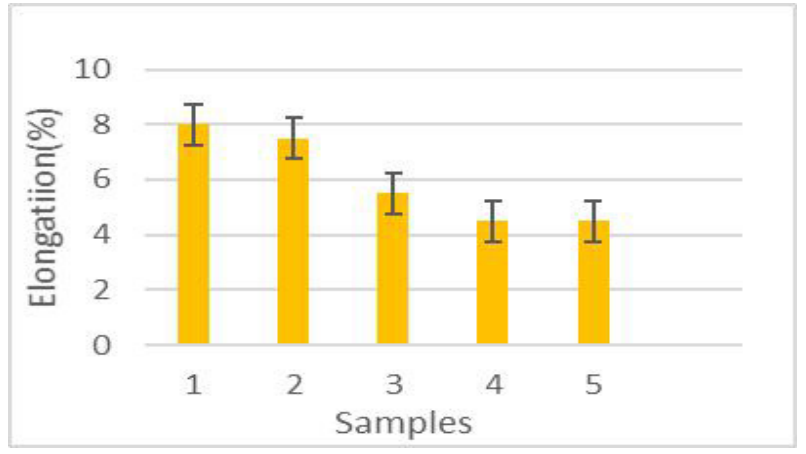

Fig. 5. Percentage of elongation.

\section{Conclusion}

From the present study, it can be concluded that cellulose/kenaf/epoxy composite was successfully prepared. Based on impact test analysis, the kenaf/epoxy matrix shows good impact strength compared to cellulose/kenaf/epoxy composites. This concludes that the addition of cellulose significantly affects the impact strength of the composite. Tensile test also showed similar observation and the analysis confirmed the negative effect on the 
ductility properties of the kenaf/epoxy matrix with the addition of cellulose. The incorporation of cellulose in the kenaf/epoxy composite reduces the hardness of the composite. However the effect to the hardness can said to be less significant compared to the impact strength.

\section{Acknowledgement}

The authors would like to acknowledge the financial support provided by Universiti Tenaga Nasional under the BOLD 2025 research grant(10289176/13/9/2017/33) scheme to promote research excellence that supports both nation's and TNB needs.

\section{References}

1. Gyanesh Joshi, Sanjay Naithani, V.K. Varshney, Surendra S. Bisht, Vikas Rana, P.K. Gupta a, Waste management. 38 (2015)

2. P. Lopez Hurtado, A. Rouilly, V. Vandenbossche, and C. Raynaud, Build. Environ. 96 (2016)

3. A. Atiqah, M. A. Maleque, M. Jawaid, and M. Iqbal, Compos. Part B Eng. 56 (2014)

4. S. Dixit, R. Goel, A. Dubey, P. R. Shivhare, and T. Bhalavi Polym. From Renew. Resour. 8 (2017)

5. Mathan Athmalingam, W.V.Vicki, IOP Conf. Ser.: Mater. Sci. Eng. 303 (2017)

6. P. Penjumras, R. B. A. Rahman, R. A. Talib, and K. Abdan, Agric. Agric. Sci. Procedia. 2 (2014)

7. H. Ku, H. Wang, N. Pattarachaiyakoop, and M. Trada, Compos. Part B Eng. 42 (2011)

8. Hathama Razooki Hasan, Muna Hasoon Sauodi, , Chemical Technology. 9 (2014) 